\title{
MECHANICAL RESPONSE OF HIGH STRENGTH FIBRE REINFORCED CONCRETE UNDER EXTREME LOADS
}

\author{
Luccioni B. ${ }^{(1)}{ }^{*}$, Isla F. ${ }^{(1)}$, Fiengo F. ${ }^{(1)}$, Codina R. ${ }^{(2)}$, Ambrosini D. ${ }^{(2)}$, Vivas J.C. ${ }^{(3)}$, Zerbino R. ${ }^{(3)}$, \\ Giaccio G. ${ }^{(4)}$ and Torrijos M.C. ${ }^{(3)}$ \\ ${ }^{(1)}$ CONICET, Structure Institute, National University of Tucumán, Argentina. \\ (2) CONICET, Engineering Faculty, National University of Cuyo, Argentina. \\ (3) CONICET, LEMIT, Engineering Faculty, National University of La Plata, Argentina. \\ (4) CIC, LEMIT, Engineering Faculty, National University of La Plata, Argentina. \\ *Corresponding author: bluccioni@herrera.unt.edu.ar
}

\begin{abstract}
High Strength Fibre Reinforced Concrete (HSFRC) presents great advantages when compared with conventional concrete under static loads and thus, it constitutes a promising material to withstand extreme loads. An experimental and numerical research carried out with the objective of developing design criteria for HSFRC use in protective structures construction is presented. The mechanical behaviour of HSFRC elements under extreme loads is experimentally and numerically analysed. Numerical models represent useful tools for the design of this type of HSFRC applications but they should be carefully calibrated and validated with experimental results. HSFRC prims and slabs including different types of hooked-end steel fibres are tested under static, blast and impact loads. Material models at the meso and the macro scale are developed, they are calibrated with characterization tests and validated with experimental results. Experimental results are analysed with the aid of numerical models showing the effect of fibre type and content under extreme load. Numerical models are able to reproduce the blast and impact tests results and give additionally information about the local and structural response under impulsive loads that could be valuable for the design of protective structures.
\end{abstract}

KEYWORDS: high strength concrete, steel fibres, blast response, impact, numerical model.

\section{INTRODUCTION}

Many researchers have proven that HSFRC has an improved behaviour with respect to conventional concretes under low and high-speed dynamic loads. These advantages make it suitable for the construction of new strategic structures or for the repair and reinforcement of existing structures against impact loads or explosions. However, the use of these materials in protective structures is still a challenge. The complexity of the behaviour added to that of impact and impact with penetration require a deep knowledge about the behaviour of the material. Moreover, robust prediction tools that allow to reproduce the behaviour under this type of actions are needed for the proper design of HSFRC elements. Several types of tests are normally used to study the behaviour of concrete and fibre reinforced concrete (FRC) under impact loads. Drop weight and pendulum impact tests are used to produce impact at 
relatively low strain rates while Split Hopkinson Pressure Barr tests and blast tests are usually performed to produce high strain rate loads [1]. The present knowledge about fibre reinforced concrete dynamic behaviour [2-4] under high strain rates is still limited and there are still some contradictory results [5]. Tensile, compressive and flexure strength increase with strain rate while toughness and postpeak ductility are absent or reduced at high strain rates [1]. It was also proved that tensile and compressive strengths, energy absorption, fracture toughness and impact resistance increase with steel fibre content [1].

Some results about the behaviour of fibre reinforced concrete elements under blast loads have been published [6-8] but experimental results concerning HSFRC and ultra-high performance fibre reinforced concrete (UHPFRC) elements under close or contact explosions are still very scarce [9-10] and it is not possible to accurately predict spalling damage [9] using available empirical methods [11].

HSFRC elements under blast loads have shown benefits in damage control, accelerations and displacements when compared to conventional concrete elements. UHPFRC elements have also presented higher ductility, lower permanent deformation, higher load bearing capacity, crack control and greater ability to absorb energy without fragmentation [12-13] than conventional concrete panels. Blast resistance increases with the increase of fibre volume and it was shown that different types of steel fibres have similar effects improving blast strength. Fibres help controlling concrete spalling and crack propagation [14]. The panels are less likely to fail presenting higher strength and extension of damage than conventional concrete specimens [15].

Available constitutive models for the simulation of FRC and composites can be classified in macro and meso models. Macro models simulate the behaviour of the composite using an equivalent homogeneous model with average properties. Constitutive laws are directly derived from tests results. The main advantage of this type of models is that they use information that is relevant at the structural scale. As a counterpart, they require large number of tests considering different fibres contents and types of loads since the fibres are not explicitly taken into account. Some of these problems can be avoided using meso-models that take into account the material components: concrete matrix, fibres and sometimes fibre/matrix interface [16-19]. This type of models has three key issues: the derivation of the fibres sewing forces through cracks, the model use for the concrete matrix and the way in which the composite behaviour is obtained from the components. The models differ in the way in which in which these three aspects are derived and combined.

Sewing forces through cracks can be obtained from pull-out tests or using meso-models [16, 20]. The fibres are explicitly modelled in some meso-mechanic approaches using different types of discrete elements [21].

Except for a few models [13,22], most of the meso-models have been developed and calibrated under static loads and are not suitable to simulate dynamic behaviour because they don't take into account strain rate effects.

The behaviour of HSFRC elements under impact and blast loads is frequently simulated with explicit codes like using concrete macro-models [23-25]. The calibration of these models is not a simple task. The use of meso-models to analyse fibres contribution and the effect of fibres geometry on mechanical properties can contribute reducing the required number of tests to calibrate these homogeneous models.

An experimental and numerical research carried out with the objective of developing design criteria for HSFRC and numerical simulation tools is presented in this paper.

\section{EXPERIMENTAL TESTS}

Experimental tests consisting on blast tests on slabs and impact tests on beams were performed in order to study de behaviour of HSFRC under extreme loads and the effect of fibres type and content on the corresponding response. 
BEFIB2020 | RILEM-fib X International Symposium on Fibre Reinforced Concrete 21-23 September 2020, Valencia, Spain

\subsection{Materials and mixtures}

Five High Strength Concretes were used for the experimental study: a plain concrete $(\mathrm{P})$ and four HSFRCs varying the fibre length and the fibre dosages. All concretes were prepared using the same base self-compacting matrix. Ordinary Portland cement $\left(730 \mathrm{~kg} / \mathrm{m}^{3}\right)$, silica fume $\left(73 \mathrm{~kg} / \mathrm{m}^{3}\right)$, calcareous filler $\left(48 \mathrm{~kg} / \mathrm{m}^{3}\right)$, natural siliceous sand $\left(490 \mathrm{~kg} / \mathrm{m}^{3}\right)$ and $12 \mathrm{~mm}$ maximum size granitic crushed stone $\left(860 \mathrm{~kg} / \mathrm{m}^{3}\right)$ were used as component materials. A set retarding plasticizer $\left(1 \mathrm{~kg} / \mathrm{m}^{3}\right)$ and a high range water reducer $\left(8.9 \mathrm{~kg} / \mathrm{m}^{3}\right)$ were used as chemical admixtures. The water / (cement + silica fume) ratio was equal to 0.24 .

Two types of hooked-end high carbon steel fibres (L30 and L60) with different lengths (30 and $60 \mathrm{~mm}$ ) and diameters ( 0.38 and $0.75 \mathrm{~mm}$ respectively) were added to HSFRC. The tensile strength of the fibres was over $2500 \mathrm{MPa}$. Two fibres contents were used 40 and $80 \mathrm{~kg} / \mathrm{m}^{3}$. HSFRC are identified with the name of the fibre followed by the fibre content (L30-40, L30-80, L60-40, L60-80).

To evaluate the compressive strength [26] and the static elastic modulus [27] $100 \mathrm{~mm} \times 200 \mathrm{~mm}$ cylinders were cast. Mean values of $114 \mathrm{MPa}$ and $40 \mathrm{GPa}$ were obtained for the compression strength and the elastic modulus respectively.

Prisms of $430 \mathrm{~mm} \times 50 \mathrm{~mm}$ x $105 \mathrm{~mm}$ with a notch of approximately $19 \mathrm{~mm}$ in the central section were used for static bending characterization [28]. They were tested under three points loading. The crack mouth opening displacement (CMOD) was registered. After the tests, specimens were separated in two parts and the fibres crossing the central section were counted. In all cases fibres were pulled out without failing.

Additionally, 40 pull-out tests of each type of fibres, including some straight fibres (cut hooked-end), were performed. The fibres were aligned with the load and the embedded length was half the fibre length. The pull-out rate was varied from 0.017 to $8.33 \mathrm{~mm} / \mathrm{s}$ obtaining similar responses for the different velocities [29].

All the specimens were cured 28 days in moist room and then stored at the laboratory environment during four months until the characterization, blast and impact tests were performed.

\subsection{Blast tests}

Square slabs of $550 \mathrm{~mm}$ side and $50 \mathrm{~mm}$ thickness were tested under blast loads. They were supported on a highly reinforced steel frame leaving a free span of $460 \mathrm{~mm}$. Three different types of blast tests were performed on the slabs varying the explosive masses and stand-off distances. In all cases, the explosive had cylindrical shape and the detonator was located in the centre of the upper surface. In Test $149 \mathrm{~g}$ of equivalent TNT were led on the slabs while in Tests 2 and 3 the explosive was supported on an expanded polystyrene block over the slabs. For Tests 2 and 3, $244 \mathrm{~g}$ and $488 \mathrm{~g}$ with a height of the explosive gravity centre over the slabs of $0.2525 \mathrm{~m}$ and $0.2725 \mathrm{~m}$ were used respectively. More details about the blast tests can be found in Refs. [29] and [30].

\subsection{Impact tests}

Prisms of $430 \mathrm{~mm} \times 75 \mathrm{~mm} \times 105 \mathrm{~mm}$ of P, L30-40 and L30-80 were used for drop weight impact tests. The prisms were mounted with $310 \mathrm{~mm}$ free span in the drop weight machine illustrated in Figure 1 where the different parts are indicated.

The projectile consisted of a $16 \mathrm{~mm}$ thick, $304 \mathrm{~mm}$ long, $5182 \mathrm{~g}$ steel plate with a semi-cylindrical tup at the bottom end. Fall heights were varied between $33 \mathrm{~mm}$ and $1000 \mathrm{~mm}$. Due to limitations of the measurement equipment range, the accelerations on the bottom of the beam were measured for fall heights up to $100 \mathrm{~mm}$, and the impact force could be measured for heights up to $429 \mathrm{~mm}$. For greater heights only the crack opening, the beam deflection and the damage pattern were registered. A piezoelectric load cell (PCB, 203 model) was used to record the impact force. An accelerometer (PCB, 353 B03 model) was used to measure accelerations. Both devices were connected to a signal conditioner 
(PCB, 482C05 model), which, in turn, was connected to two signal acquisition boards (Measurement Computing, USB-1608FS model). The signal acquisition rate was $50 \mathrm{kHz}$.
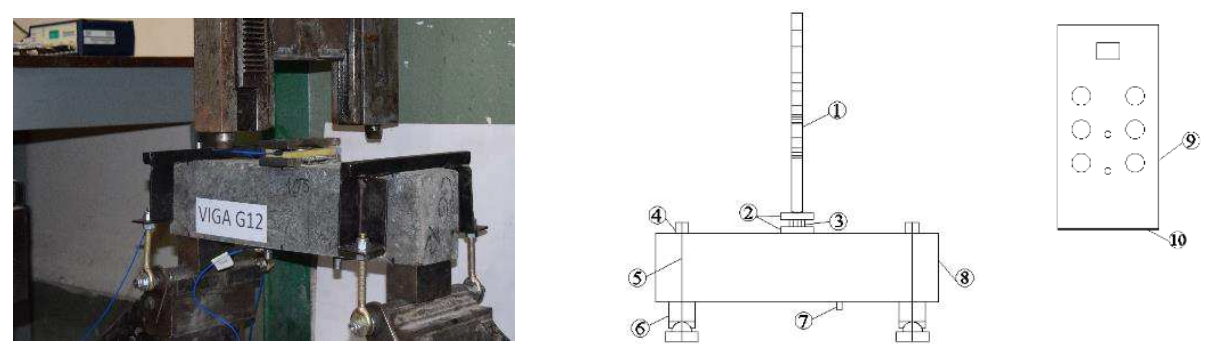

Figure 1. Impact test setup. (1) Projectile, (2) metal plates, (3) load cell, (4) metal bar that fixes the specimen to the support, (5) metal rod that links the metal bar and metal supports, (6) metal supports, (7) accelerometer, (8) HARRF beam, (9) projectile side view and (10) projectile semi-cylindrical tup.

\section{NUMERICAL MODELS}

The numerical simulation of HSFRC slabs under blast loads and HSFRC was performed with hydrocodes using concrete macro-models calibrated to reproduce the behaviour of HSFRC with different types and contents of steel fibres. A meso-model developed by the authors [18] was first used in order to obtain the parameters required for the macro-models.

\subsection{Meso-model for HSFRC}

A meso-model was used to obtain the properties [19] for the homogeneous equivalent models available in hydrocodes for the simulation of HSFRC elements under blast and impact loads. HSFRC is assumed as a composite material made of a high strength concrete matrix with dispersed fibres oriented in a finite number $\mathrm{n}$ of discrete orientations. A modification of classical mixture theory is used to take into account orthotropic behaviour of fibres and their slip respect to the matrix in a simplified way [18]. Concrete matrix is modelled with an elastoplastic model [31] and steel fibres are assumed as orthotropic elastoplastic inclusions that can debond and slip from the matrix. Constitutive equations of fibres are modified in order to include this inelastic phenomenon without explicitly modelling the interface. The model requires concrete properties, fibres material, geometry, distribution and orientation as input data. The fibres bond-slip behaviour is obtained from a pull-out model [30]. The strain rate dependence is explicitly taken into account in the constitutive models of the components. The model was proved to accurately simulate the 2D static behaviour of steel fibre reinforced concrete [18] and UHPFRC under high strain rates [19].

First, pull out tests of straight fibres obtained from both fibres used were numerically simulated. In this way, the sliding threshold, the residual tangential strength and the friction coefficient were calibrated. Then, the load-displacement curves for hooked-end fibres were numerically reproduced with the pullout model. The results for aligned fibres are presented in Figure 2 where a good agreement between numerical results and average experimental response is observed.

$\mathrm{P}$ beams results were used to calibrate concrete tension strength and fracture energy. Then, the flexure response of HSFRC notched beams with different fibres contents was simulated with the meso-model described and compared with experimental results in order to check the model validity. The fibres were supposed to be located in vertical planes, $40 \%$ in axial direction, $30 \%$ at $60^{\circ}$ and 30 at $-60 \%$. This fibre distribution is only valid for these beams and should be approximated in correspondence with the actual fibre distribution in other cases. The pull-out responses for different fibre orientations were be obtained 
BEFIB2020 | RILEM-fib X International Symposium on Fibre Reinforced Concrete 21-23 September 2020, Valencia, Spain

with the pull-out model. As illustration, the flexure responses of HSFRC with different contents of fibres L60 are shown in Figure 3. These fibre contents correspond to the actual fibre contents verified after the tests.

Once the material properties and the model were validated, compression and tension response curves for the different HSFRC were obtained. These curves were used as input data for the macro- models.

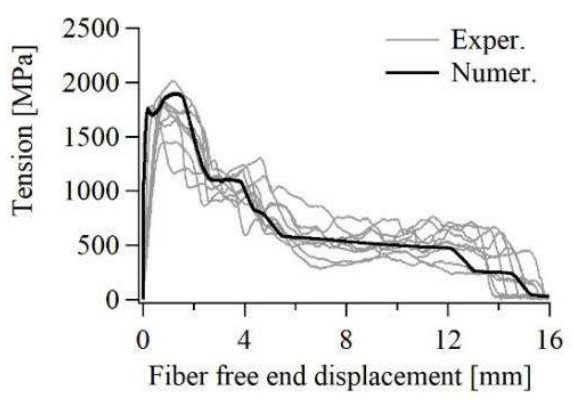

a)

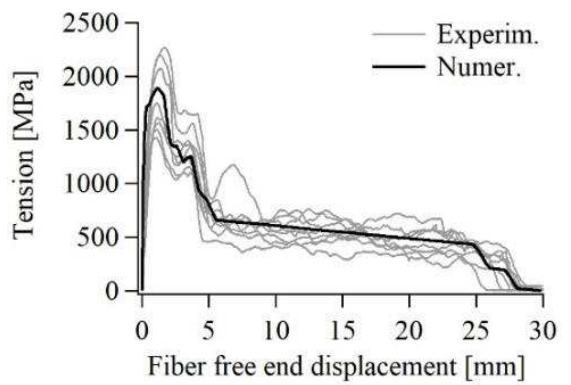

b)

Figure 2. Pull-out tests of aligned fibres. a) Fibres L30, b) Fibres L60.
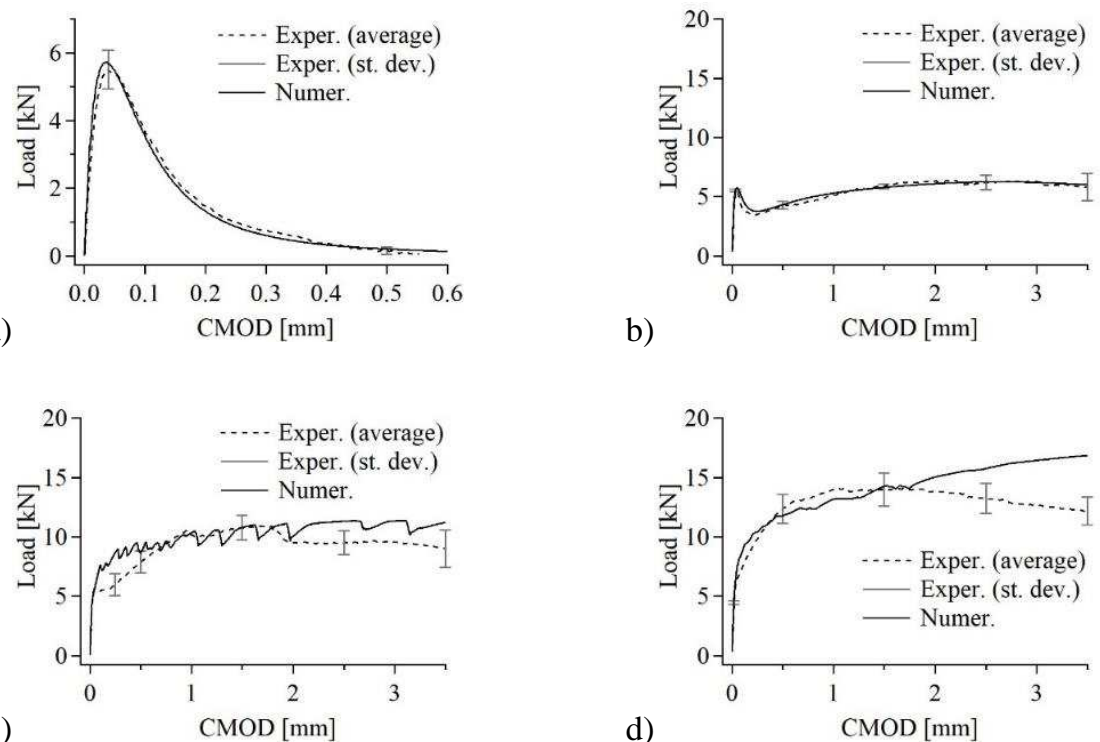

Figure 3. Flexure tests. a) P, b) L60-0.25\%, c) L60-0.5 \%, d) L60-0.75\%.

\subsection{Numerical simulation of blast tests}

Blast tests were numerically modelled with AUTODYN [32]. The model consisted of the air volume, where the slabs were immersed and the blast wave was generated and propagated, the slabs and the support. The ideal gas equation of state (EOS) was used for the air while JWL EOS was used for TNT. Standard material parameters available in AUTODYN material library were used for air and TNT [32]; 
The problem was modelled from the beginning (explosive detonation) with a 3D model and using an Euler Gudunov processor. A Lagrange processor with 3D brick elements of $5 \mathrm{~mm}$ side was used for the slabs while shell elements were used for the supports. Euler Lagrange interaction was defined between air and the slab and the supports.

Concrete RHT model [33] in combination with p- $\alpha$ equation of state (EOS) was used for HSC and HSFRC. Based on previous numerical results, the effect of adding different steel fibres and fibres contents was taken into account modifying the main parameters related to tension strength and ductility (failure strain and erosion limit). More details about this calibration can be found in Ref. [30].

\subsection{Numerical simulation of impact tests}

The numerical simulation of impact tests was performed with LS-Dyna [34]. All elements except for the metallic rods were simulated using brick elements (ELFORM 1) of $5 \mathrm{~mm}$ for the beam and the supports and $3 \mathrm{~mm}$ side for the projectile and load cell. Truss elements were used for the rods.

$\mathrm{K} \& \mathrm{C}$ model [35] calibrated using the described meso-model was used for HSC and HSFRC. Basically, the parameters of the compression and tension hardening curves for the different fibres contents were obtained. A penalty formulation (soft 0 ) was used for contact and friction was taken into account. Rayleigh damping with parameters obtained from calibration with experimental results was considered.

\section{EXPERIMENTAL AND NUMERICAL RESULTS}

\subsection{Blast tests results}

The damage patterns on front and rear face of some of the slabs after blast Tests 1 and 3 are shown in Figures 4 and 5 where numerical results are also included for comparison. The rest of the results can be found in Ref. [30].

In all tests performed on plain concrete brittle flexure failure of the slabs was obtained due to the reduced slab thickness and the brittle nature of HSC. An important concrete spalling at the rear face that reaches the front face for contact explosion (Test 1). The damage patterns obtained for HSFRC slabs were strongly different from those of P slabs. No HSFRC slab tested under contact explosions (blast Test 1) exhibited flexure failure and they preserved integrity after the tests (Figure 4). Flexure cracks can hardly be identified. The front faces of the slabs presented a small eroded zone like a crater produced by the high pressures originated by the detonation of the explosive in contact with concrete. The crater dimensions were reduced when fibre content was increased but only a slight reduction of crater dimensions was obtained for fibres L30 when doubling the fibre volume content. Slabs containing fibres L30 (shorter fibres) exhibit smaller craters on front face and spalling on rear face than slabs with fibres L60 with the same fibre content showing that for the same fibre content, shorter fibres are more efficient controlling concrete cratering and spalling than longer fibres.

In blast Test 2 slab P was fractured while L30-40 and L60-40 slabs presented flexure cracks at the rear face and slabs L30-80 and L60-80 exhibited almost imperceptible flexure cracks. Erosion in a reduced zone was observed in the front face while a bigger spalling zone was created at the rear face. In contrast with L60-40, slab L30-40 did not exhibit either crater or spalling showing the greater effect of shorter fibres controlling these types of damage. Increasing the fibre, content flexure cracks and spalling zone were reduced.

For the case of blast Test 3 (Figure 5). slabs P and L30-40 were fractured but L60-40 presented wide flexure cracks suggesting that longer fibres are more efficient controlling flexure cracks than shorter fibres. As in the rest of the blast tests, fibres were pulled-out without failing in all cases.

A good agreement between numerical and experimental final damage patterns was obtained but the numerical simulations show that homogeneous models are not able to reproduce HSFRC behaviour under the whole range of scaled distances to reproduce flexure failure, cratering and spalling [30]. 
BEFIB2020 | RILEM-fib X International Symposium on Fibre Reinforced Concrete 21-23 September 2020, Valencia, Spain

Face

ค

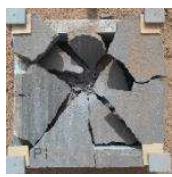

Front

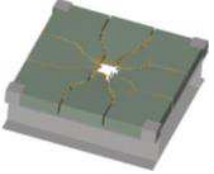

古
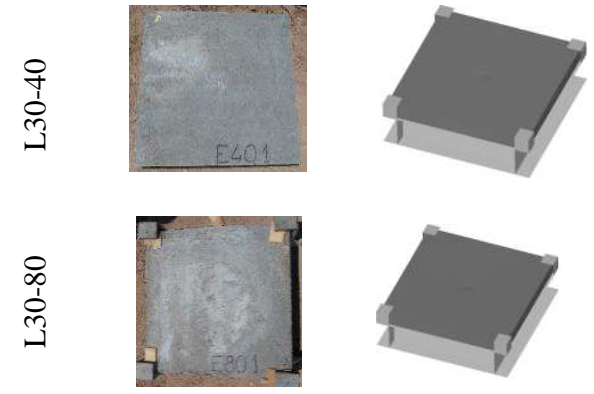
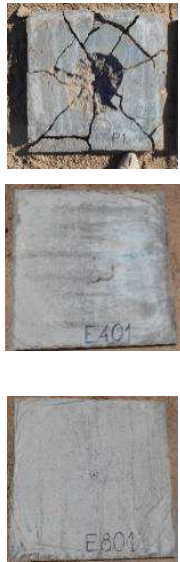

Rear
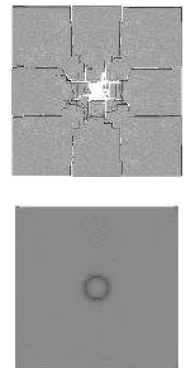

Figure 4. Experimental results and numerical simulation of blast Test 1.

Face

Front

Rear

a
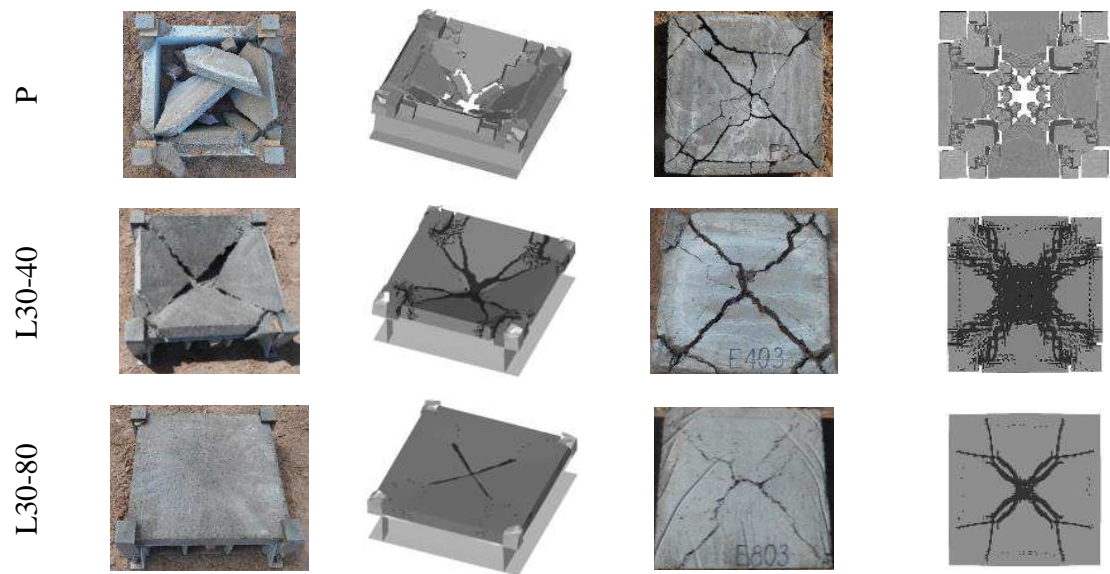

Figure 5. Experimental results and numerical simulation of blast Test 3 .

\subsection{Impact tests results}

Only P and HSFRCs with the shorter fibres have been tested under impact loads until now. The comparison of numerical and experimental results for two fall heights $\mathrm{H}$ on L30-80 beam are presented in Figure 6. It can be observed that numerical acceleration peaks (a_max $=474 \mathrm{~g}$, a_min $=-400 \mathrm{~g}$ ) are greater than those registered in the tests $\left(\mathrm{a} \_\max =377 \mathrm{~g}\right.$, a_min $=-334 \mathrm{~g}$ ). Nevertheless, the envelopes of both records are similar. The impact forces histories are satisfactorily reproduced 

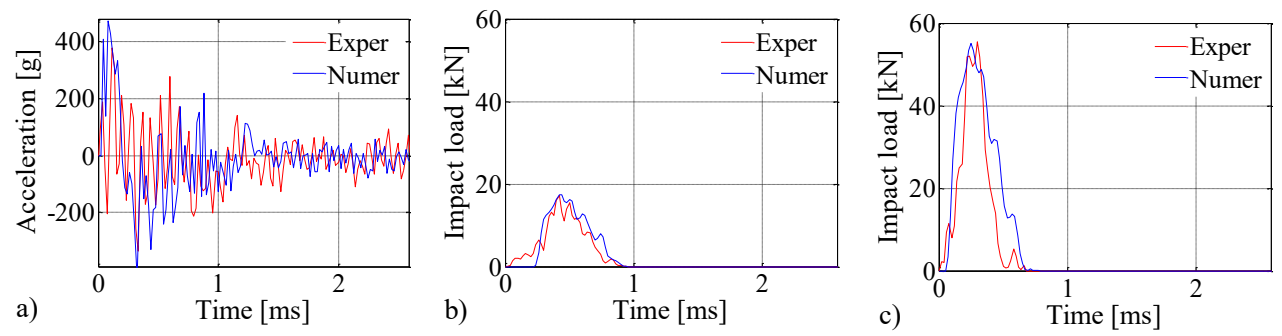

Figure 6. Impact (L30-80 beam) a) Acceleration $\mathrm{H}=33 \mathrm{~mm}$ b) Load H=33 mm c) Load H=300 mm.

The permanent deflections numerically obtained for the first impact and those registered in the tests for three consecutive impacts from the same height are presented in Figure 7 for two fibres contents. The results for each height correspond to a different specimen. For all the heights above $100 \mathrm{~mm}$ the fibres were pulled-out without failing. The deflections for the first impact are well reproduced by the numerical model. The comparison of Figures $7 \mathrm{a}$ and $\mathrm{b}$ shows the deflection are reduced when the fibre content is increased but the effect is more important for the repeated impacts.
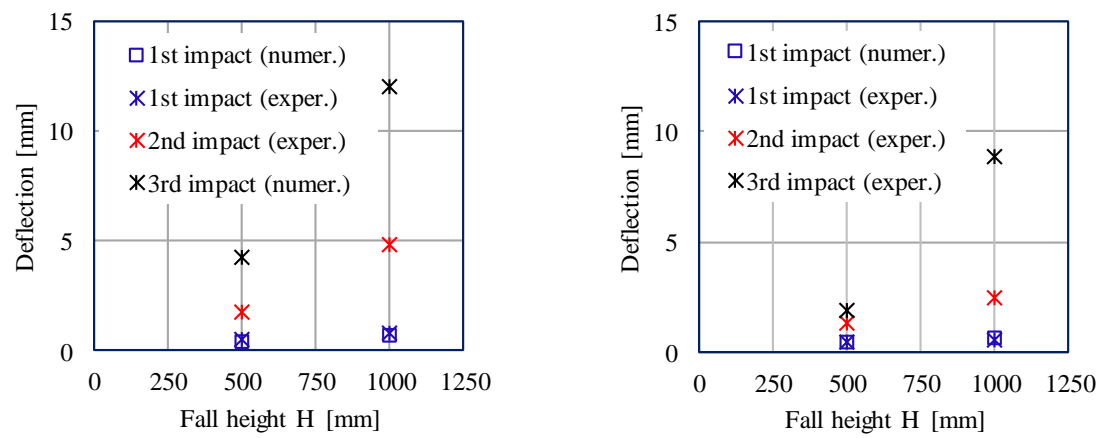

Figure 7. Deflections a) Beam L30-40 b) Beam L30-80.

\section{CONCLUSIONS}

The effect of incorporating different contents of hooked-end high carbon steel fibres of different lengths in a $\mathrm{HSC}$ on blast and impact response was experimentally and numerically studied. The following conclusions are only valid for the particular concrete composition chosen for the testing. Different casting techniques or mix designs could result in different fibre behaviour.

- The incorporation of fibres, not only increases residual loading capacity and toughness under static loads but also significantly improves impact and blast behaviour. Flexural crack thickness, erosion and spalling zones dimensions and permanent deflections are reduced with the increase fibre content.

- For the same fibre content, shorter fibres lead to a greater improvement of the matrix behaviour and they are more effective controlling cratering and spalling.

- Numerical models developed are able to approximately reproduce static, blast and impact behaviour but further development should be performed mainly related to erosion criteria and 
BEFIB2020 | RILEM-fib X International Symposium on Fibre Reinforced Concrete

21-23 September 2020, Valencia, Spain

limits since it is difficult to reproduce cater and spalling under blast loads and fracture under impact loads with the available erosion models.

\section{ACKNOWLEDGEMENTS}

The cooperation in the blast tests of Prof. Oscar Curadelli, Bioeng. Gabriel Houri, Dr. Eng. Martín Domizio and Dr. Eng Hernán Garrido are specially acknowledged. The authors wish to thank the financial support of National Agency for Scientific and Technological Promotion, National Scientific and Technological Research Council (CONICET), LEMIT-CIC, National University of Tucumán Research Council (CIUNT) and National University of Cuyo. The companies Cementos Avellaneda S.A., Ferrocement S.A, N.V. Bekaert S.A. and Sika Argentina S.A.I.C. that provided the cement, the silica fume, the steel fibres and the chemical admixtures are also greatly acknowledged.

\section{REFERENCES}

[1] Soufeiani, L., Raman, S., Bin Jumaat, M.Z., Alengaram, U.J., Ghadyani, U.J. and Mendis, P., 'Influences of the volume fraction and shape of steel fibers on fiber reinforced concrete subjected to dynamic loading - A review', Eng. Struc. 124 (2016) 405-417.

[2] Millard, S.G., Molyneaux, T.C., Barnett, S.J. and Gao, X., 'Dynamic enhancement of blastresistant ultrahigh performance fibre-reinforced concrete under flexural and shear loading', Int. $J$. Impact Eng. 37 (2010) 405-413.

[3] Wang, S., Zhang, M-H. and Quek, S.T., 'Mechanical behavior of fiber-reinforced high-strength concrete subjected to high strain-rate compressive loading', Constr. Build. Mater. 31 (2012) 1-11.

[4] Tran, N.T., Tran, T.K., Kim, D.J., 'High rate response of ultra-high-performance fiber-reinforced concretes under direct tension', Cement Concrete Res. 69 (2015) 72-87.

[5] Caverzan, A., Cadoni, E., and di Prisco, M., 'Tensile behaviour of high performance fibrereinforced cementitious composites at high strain rates' Int. J. Impact Eng. 45 (2012) 28-38.

[6] Wang, Z.L., Konietzky, H. and Huang, R.Y., 'Elastic-plastic-hydrodynamic analysis of crater blasting in steel fiber reinforced concrete', Theor Appl Fract Mec 52 (2009) 111-116.

[7] Pantelides, C.P., Garfield, T.T., Richins, W.D., Larson, T.K. and Blakeley, J.E., 'Reinforced concrete and fiber reinforced concrete panels subjected to blast detonations and post-blast static tests', Eng. Struct. 76 (2014), 24-33.

[8] Foglar, M. and Kovar, M., 'Conclusions from experimental testing of blast resistance of FRC and RC bridge decks', Int. J. Impact Eng. 59 (2013) 18-28.

[9] Li, J., Wu, Ch., Hao, H., Wang, Z. and Su, Y., 'Experimental investigation of ultra-high performance concrete slabs under contact explosions', Int. J. Impact Eng. 93 (2016) 62-75.

[10] Nam, J., Kim, H. and Kim, G. 'Experimental Investigation on the blast resistance of fiberreinforced cementitious composite panels subjected to contact explosions', Int. J. Conc. Struc. Mat. 11(1) (2017) 29-43.

[11] Li, J. and Hao, H., 'Numerical study of concrete spall damage to blast loads', Int. J. Impact Eng. 68 (2014) 41-55.

[12] Aoude, H., Dagenais, F.P., Burrell, R.P. and Saatcioglu, M., 'Behavior of ultra-high performance fiber reinforced concrete columns under blast loading', Int. J. Impact Eng. 80 (2015) 185-202.

[13] Ellis, B.D., Di Paolo, B.P., McDowell, D.L. and Zhou, M., 'Experimental investigation and multiscale modeling of ultra-high performance concrete panels subject to blast loading', Int. $J$ Impact Eng. 69 (2014) 95-103.

[14] Mao, L., Barnettm S.J., Tyas, A., Warren, J., Schleyer, G.K. and Zaini, S.S., 'Response of small scale ultra high performance fibre reinforced concrete slabs to blast loading', Const. Build. Mat. 93(15) 2015 822-30. 
BEFIB2020 | RILEM-fib X International Symposium on Fibre Reinforced Concrete 21-23 September 2020, Valencia, Spain

[15] Thoma, K., Stolz, A. and Millon, O., 'Performance and suitability of ultra-high-performance concrete under a broad range of dynamic loadings', in 'Advances in Protective Structures Research'. IAPS Special publication 1, London Taylor \& Francis, London (2012) 65-96.

[16] Caggiano, A. and Martinelli, E., 'A unified formulation for simulating the bond behaviour of fibres in cementitious materials', Mat. Design 42 (2012) 204-213.

[17] Oliver, J., Mora, D., Huespe, A. and Weyler, R., 'A micromorphic model for steel fiber reinforced concrete', Int. J. Solids Struc. 49 (2012) 2990-3007.

[18] Luccioni, B., Ruano, G., Isla, F., Zerbino, R. and Giaccio, G., 'A Simple approach to model SFRC', Constr. Build. Mat. 37 (2012) 111-124.

[19] Luccioni, B., Isla, F., Forni, D.and Cadoni, E., 'Modelling UHPFRC tension behavior under high strain rates'. Cem. Conc. Comp. 91 (2018) 209-220.

[20] Cunha, V.M., Barros, J.A.O. and Sena-Cruz, J.M., 'A finite element model with discrete embedded elements for fibre reinforced composites', Comp. \& Structs $94-95$ (2012) 22-33.

[21] Fang, Q. and Zhang, J., 'Three-dimensional modelling of steel fiber reinforced concrete material under intense dynamic loading', Constr. Build. Mater. 44 (2013) 118-132.

[22] Bragov, A.M., Karihaloo, B.L., Petrov, Y.V., Konstantinov, A.Y., Lamzin, D.A., Lomunov, A.K. and Smirnov, I.V. 'High-rate deformation and fracture of fiber reinforced concrete', J. App. Mech. Tech. Phys. 53(6) (2012) 926-933.

[23] Li, J. and Zhang, Y., 'Evaluation of constitutive models of hybrid-fibre engineered cementitious composites under dynamic loadings', Const. Build. Mat. 30 (2012) 149-160.

[24] Mao, L. and Barnett, S.J., 'Investigation of toughness of ultra high performance fibre reinforced concrete (UHPFRC) beam under impact loading', Int. J. Impact Eng. 99 (2016) 26-36.

[25] Guo, W., Fan, W., Shao, X., Shen, D. and Chen, B., 'Constitutive model of ultra-high-performance fiber-reinforced concrete for low-velocity impact', Comp. Struc. 185 (2018) 307-326.

[26] ASTM C39/ C39M - 15 Standard Test method for Compressive strength of cylindrical Concrete Specimens. Book of Standards. Volume 04.02. DOI: 10.1520/C0039_C0039M.

[27] ASTM C469/ C469M - 14 Standard Test method for Static Modulus of Elasticity and Poisson's Ratio of Concrete in Compression. Book of Standards. Volume 04.02. DOI: 10.1520/C0469_C0469M.

[28] EN 14651:2005 Test method for metallic fibered concrete - Measuring the flexural tensile strength (limit of proportionality (LOP), residual). CEN-European Committee for Standardization, Brussels, (2005) 1-17.

[29] Luccioni, B., Isla, F., Codina, R., Ambrosini, D., Zerbino, R., Giaccio, G. and Torrijos, M.C., 'Effect of Steel fibers on static and blast response of high strength concrete', Int, J. Impact Eng. 107 (2017) 23-37.

[30] Luccioni, B., Isla, F., Codina, R., Ambrosini, D., Zerbino, R., Giaccio, G. and Torrijos, M.C., 'Experimental and numerical analysis of blast response of High Strength Fiber Reinforced Concrete slabs', Eng. Struc, 175 (2018) 113-122.

[31] Luccioni, B. and Rougier, V., 'A plastic damage approach for confined concrete', Comput. \& Struct. 83 (2005) 2238-2256.

[32] ANSYS, AUTODYN Version 18.1 User's Manual, 2017.

[33] Riedel, W., Kawai, N. and Kondo, K., 'Numerical assessment for impact strength measurements in concrete materials', Int. J. Impact Eng. 36 (2009) 283-293.

[34] LSTC, LS-Dyna Theory manual, Livermore Software Tech. Corp., 2018.

[35] Malvar, L.J., Crawford, J.E., Wesevich, J.W. and Simons, D.A., 'A plasticity concrete material model for DYNA3D', Int. J. Impact Eng. 19 (1997) 847-873. 